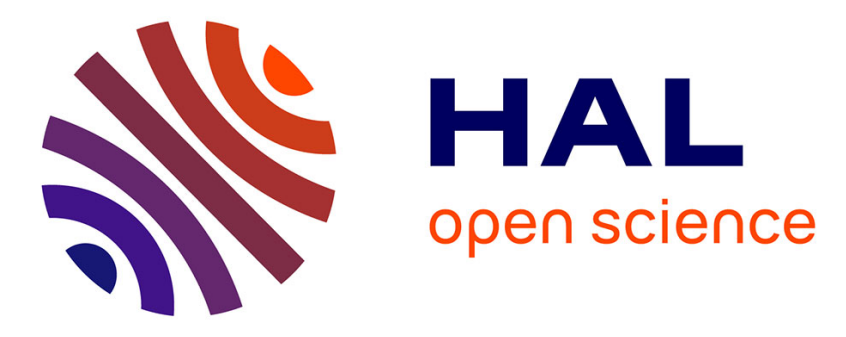

\title{
A wear damage assessment of high temperature forging tool
}

Elodie Cabrol, Christine Boher, Vanessa Vidal, Farhad Rezai-Aria, Fabienne Touratier

\section{- To cite this version:}

Elodie Cabrol, Christine Boher, Vanessa Vidal, Farhad Rezai-Aria, Fabienne Touratier. A wear damage assessment of high temperature forging tool. Advanced Materials Research, 2014, 966-967, p.103110. 10.4028/www.scientific.net/AMR.966-967.103 . hal-01713986

\section{HAL Id: hal-01713986 https://imt-mines-albi.hal.science/hal-01713986}

Submitted on 25 Sep 2018

HAL is a multi-disciplinary open access archive for the deposit and dissemination of scientific research documents, whether they are published or not. The documents may come from teaching and research institutions in France or abroad, or from public or private research centers.
L'archive ouverte pluridisciplinaire HAL, est destinée au dépôt et à la diffusion de documents scientifiques de niveau recherche, publiés ou non, émanant des établissements d'enseignement et de recherche français ou étrangers, des laboratoires publics ou privés. 


\author{
A wear damage assessment of high temperature forging tool \\ Elodie Cabrol ${ }^{1-2, a}$, Christine Boher ${ }^{1, b^{*}}$, Vanessa Vidal ${ }^{1, c}$, Farhad Rezai-Aria ${ }^{1, d}$ \\ and Fabienne Touratier ${ }^{2, \mathrm{e}}$ \\ ${ }^{1}$ Université de Toulouse, Mines Albi, ICA (Institut Clément Ader), Campus Jarlard, F-81013 Albi \\ cedex 09, France \\ ${ }^{2}$ Aubert \& Duval - F- 09102 Pamiers Cedex - France \\ aecabrol@mines-albi.fr, ${ }^{b} b o h e r @ m i n e s-a l b i . f r, ~ c v v i d a l @ m i n e s-a l b i . f r, ~{ }^{d}$ rezai@mines-albi.fr, \\ efabienne.touratier@eramet-aubertduval.com
}

Keywords: Hardfaced hot forging die, Stellite 21, MIG welding process, texture, plastic deformation, tribological test

\begin{abstract}
High temperature forging tools are highly damaged by wear shearing under cyclic loading which reduces the life of tools. In real conditions, depending upon the tool areas, the level of wear can change. The surfaces of tools can be treated by cobalt-based hardfacing using different welding processes. This study focuses on tribological damages of Stellite 21 deposited by MIG process. Wear tests are carried out at room and high temperature on a ring on disc tribometer under high normal load. Different testing conditions are examined. The surface plastic strain due to the friction shear stresses is demonstrated by different methods like SEM observations, micro-hardness measurements and XRD analyses.

More particularly, it is shown that the initial (200) crystallographic preferred orientation due to the welding process is modified into (111) crystallographic preferred orientation due to shear stresses regardless the loading. Moreover, a relationship between the gradient of the plastic shear strain at the friction subsurface and the level of the micro-hardness measurement has been established. In regard of the results, when the shear strain exceeds a threshold, the micro-hardness measurement is stabilised. The ultimate value could be induced by the stacking fault energy that is considered as weak in Stellites.
\end{abstract}

\title{
Introduction
}

The cobalt-based alloys like Stellite are used in many applicative fields to protect surfaces against wear even at high temperature. These alloys are often used as hardfacing materials. Their typical microstructure consists of a cobalt-rich dendritic matrix surrounded by chromium and molybdenum-rich carbides $\left(\mathrm{M}_{7} \mathrm{C}_{3}, \mathrm{M}_{23} \mathrm{C}_{6}\right.$ and $\left.\mathrm{M}_{6} \mathrm{C}\right)$ [1-5].

For Stellite, the crystallographic structure of the matrix is face-centred cubic (FCC) even if its thermodynamically stable phase should be hexagonal close-packed (HCP). Several authors identified that under very high contact pressures, during friction, the metastable FCC structure is transformed into HCP structure. This transformation, called strain-induced transformation considered as martensitic transformation, is mainly observed under high shear stresses [6-10] and is facilitated by the low stacking-fault energy of Stellites [11].

Persson et al. [7] have also observed under high normal load and several strokes, that within the upper friction layer (a few nanometres thick) the cobalt HCP planes are tilted and aligned parallel to the sliding surface. This tilt could be responsible of the low friction factor.

In addition a large work-hardening under shear stresses also occurs with an increase of the hardness [7,12-14].

To increase tool lifetime, hardfacing of hot forging die surfaces is commonly applied. Cobaltbased superalloys (Stellite 6 - Stellite 21) or Nickel-based (Inconel 625 or 718) deposited by MIG welding processes are often used as hardfacing coatings because of their wear and oxidation resistances at high temperature $\left(>550^{\circ} \mathrm{C}\right)$.

Forging under very high loading, high temperature and for prolonged contact time between the forged piece and the die (aeronautical parts in Inconel grade) induces large plastic deformation in 
the tool radii which is the main damage mechanism limiting the lifetime of the tools to a few forged pieces.

In this specific applicative field, studies are essentially focused on the improvement of the hardfacing machining and relationships between deposition process parameters and mechanical properties of the hardfacing coatings $[12,13]$.

This study focuses on the main tribological damages which can be observed in Stellite 21 deposited by MIG process under tribological tests at room and high temperature. Different testing conditions are examined and can highlight four wear damages that are very close together: compaction of wear particles, subsurface plastic deformation, subsurface work-hardening and surface texturation. The damages due to the friction shear stresses are demonstrated by different methods like SEM observations, micro-hardness measurements and XRD analyses.

\section{Experimental procedure and investigated materials}

Experimental procedure. Tribological tests are performed on a high load ring on disc tribometer (Fig. 1) in configuration cylinder (ring contact surface) on a flat disk (Fig. 2). The normal force is applied by dead weights applied via a level arm for high loads (up to $800 \mathrm{DaN}$ ). The disk is driven by a stepping motor and its movement can be a continuous rotation or a reciprocating rotation. A three-zone resistance furnace is used for high temperature tests (up to $1000^{\circ} \mathrm{C}$ ).

The normal force and the tangential forces are continuously measured by sensors and recorded by a Labview software. As presented in Fig. 2, the ring (upper sample) is a 40NiCrMo18 steel grade $\left(\mathrm{AD} 820^{\circledR}\right)$ hardfaced with Stellite $21^{\circledR}$ and the disk (bottom sample) is a Nickel-based superalloy grade (Inconel $718^{\circledR}$ ). The chemical compositions are given in Table 1.

The Stellite 21 hardfacing is deposited in a single layer on a AD820 steel plate by using metal inert gas welding (MIG) process. The rings are then machined in the hardfaced plate and the final coating thickness is about $1 \mathrm{~mm}$.

Several tribological parameters have been tested in order to obtain surface damages similar to hot forging die damages observed in aeronautic field. For that, normal loads in the range of 100 $\mathrm{DaN}$ up to $800 \mathrm{DaN}$, reciprocating and continuous rotation movements with speeds in the range of $60 \mathrm{~mm} / \mathrm{sec}$ up to $160 \mathrm{~mm} / \mathrm{sec}$ and test durations from $30 \mathrm{~min}$ to 12 hours have been tested. The results of these different conditions allow achieving a level of Stellite 21 damages that can be representative of industrial damages, especially in terms of level of micro-hardness. For this study, the tribological tests are presented in Table 2.

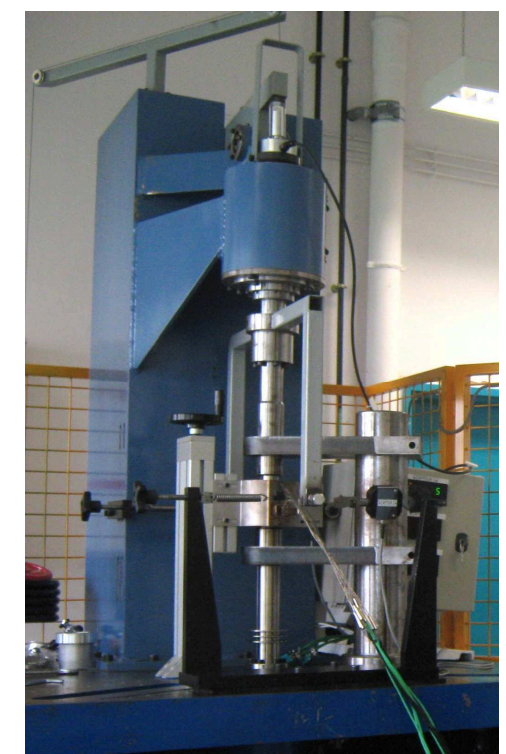

Fig. 1: Photo of the high load tribometer (equipped with a three-zone resistive furnace)

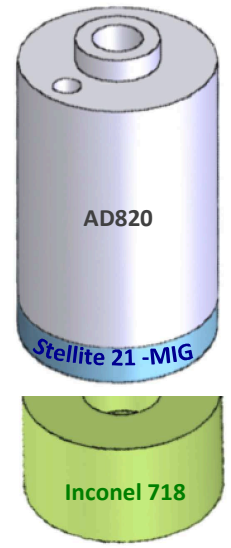

Fig. 2: Scheme of the tribological tests samples 
Table 1: Chemical composition of the studied materials [wt.\%]

\begin{tabular}{cccccccccccc} 
& $\mathbf{C}$ & $\mathbf{C r}$ & $\mathbf{M o}$ & $\mathbf{N i}$ & $\mathbf{M n}$ & $\mathbf{S i}$ & $\mathbf{N b}$ & $\mathbf{T i}$ & $\mathbf{A l}$ & $\mathbf{F e}$ & $\mathbf{C o}$ \\
\hline Stellite 21 & 0.27 & 28.0 & 5.00 & 2.40 & 1.00 & 1.30 & - & - & - & 3.50 & Bal. \\
\hline 40NiCrMo18 & 0.40 & 1.50 & 0.50 & 4.50 & - & - & - & - & - & Bal. & - \\
\hline Inconel718 & 0.04 & 18.00 & 3.00 & Bal. & - & - & 5.20 & 0.90 & 0.50 & 18.50 & - \\
\hline
\end{tabular}

Table 2: Tribological parameters used in this study

\begin{tabular}{cccccc}
$\begin{array}{c}\text { Tribological } \\
\text { test number }\end{array}$ & $\begin{array}{c}\text { Furnace } \\
\text { temperature } \\
{\left[{ }^{\circ} \mathbf{C}\right]}\end{array}$ & $\begin{array}{c}\text { Normal } \\
\text { load } \\
{[\mathbf{D a N}]}\end{array}$ & $\begin{array}{c}\text { Hertz contact } \\
\text { pressure } \\
{[\mathbf{M P a}]}\end{array}$ & $\begin{array}{c}\text { Rotation } \\
\text { movement } \\
{[\mathbf{r p m}]}\end{array}$ & $\begin{array}{c}\text { Test } \\
\text { duration } \\
{[\mathbf{m i n}]}\end{array}$ \\
\hline 1 & 20 & 500 & 472 & 50 & 120 \\
\hline 2 & 20 & 300 & 365 & 50 & 360 \\
\hline 3 & 450 & 500 & 472 & 60 & 30 \\
\hline 4 & 450 & 200 & 298 & 60 & 30 \\
\hline 5 & 600 & 500 & 472 & 60 & 30 \\
\hline
\end{tabular}

Microstructural observations and chemical compositions are performed on a FEI Nova Nano SEM. Micro-hardness measurements are realized on cross-sections using a Vickers indenter with loads of $50 \mathrm{~g}, 100 \mathrm{~g}$ and $300 \mathrm{~g}$. XRD patterns as well as pole figure measurements are performed using a Panalytical X'Pert PRO diffractometer with a cobalt radiation source $(\lambda \mathrm{K} \alpha=1,789 \AA)$.

Standard $\theta-2 \theta$ scans are obtained from the surface specimens before and after tribological tests using an X'Celerator detector. Texture measurements are performed using an open Eulerian Cradle holder and a parallel plate collimator $0.18^{\circ}$ detector. (111) and (200) pole figures are realized for a tilt in range of $0^{\circ}$ up to $75^{\circ}$ and a rotation angle $0^{\circ}$ to $360^{\circ}$. Surface topographic measurements are performed using an AltiSurf520 extended field confocal microscope.

Phase composition and crystallography of MIG processed Stellite 21. MIG processed Stellite 21 microstructures consist in cobalt rich dendrites and interdendritic regions containing primary chromium and molybdenum rich carbides. In these hardfacing coatings, iron coming from the dilution during the welding process is concentrated only in the dendritic matrix. The presence of a few aluminium oxides can be also noticed.

Dendrite solidification is oriented perpendicularly to the substrate-hardfacing interface, according to the thermal gradient. As a result, unaffected Stellite presents a morphological texture (Fig. 3). Tribological tests modify this microstructure as presented in the 3.2 paragraph.

On the XRD pattern of the unaffected Stellite surface (in the $\theta-2 \theta$ configuration), all the peaks can be indexed in accordance with the face-centred cubic structure (FCC) of the cobalt. Comparison of the intensity of the Bragg peaks from $\theta-2 \theta$ scans with data from the standard cobalt reference (JCPDS 15-806) can be a convenient way to characterize the development of texture. For that, evolutions of the relative intensities of the FCC peaks are computed on Fig. 4. These measurements show that during welding process, Stellite develop a (200) texture (with (200) planes parallel to the surface).

So, in order to complete this $\theta-2 \theta$ analyses, texture measurements have been undertaken on the two more intense peaks of the FCC structure of the cobalt: (111) and (200). The pole figures show that Stellite 21 deposited by MIG process presents a crystallographic texture, in addition to the morphological texture. Indeed, as shown on the (200) pole figure, Stellite 21 develops a major $<200>$ texture perpendicular to the surface (parallel to solidification direction) during the deposition process. 


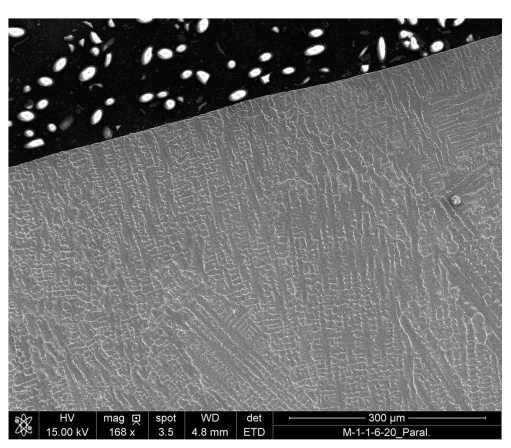

Fig. 3: Typical microstructure of a Stellite hardfacing deposited by MIG process: morphological texture

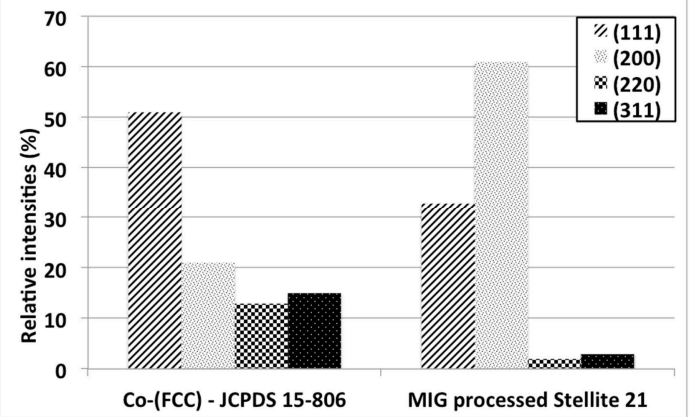

Fig. 4: Comparison of the peak relative intensities of the MIG processed Stellite 21 with cobalt JCPDS reference ones

\section{Tribological results and discussion}

Evolution of the friction factor and wear measurements. The dependence of the load and test temperature on the friction factor is investigated by tests number 2 to 5 which have been realized using a $60 \mathrm{rpm}$ continuous rotation movement during $30 \mathrm{~min}$. For all this tests, friction factor evolution versus time is rather smooth. The average friction factor is sensitive to normal load (comparison between tests $n^{\circ} 3$ and $n^{\circ} 4$ ) but no significant dependence is observed with test temperature (comparisons between tests $n^{\circ} 2, n^{\circ} 4$ and $n^{\circ} 5$ ) (Table 3).

Table 3: Friction friction for different temperatures and normal loads

\begin{tabular}{cccc}
$\begin{array}{c}\text { Tribological } \\
\text { test number }\end{array}$ & $\begin{array}{c}\text { Furnace temperature } \\
{\left[{ }^{\circ} \mathbf{C}\right]}\end{array}$ & $\begin{array}{c}\text { Normal load } \\
{[\text { DaN] }}\end{array}$ & $\begin{array}{c}\text { Average friction } \\
\text { factor }\end{array}$ \\
\hline 2 & 20 & 500 & $\mathbf{0 . 3 3} \pm \mathbf{0 . 0 4}$ \\
\hline 3 & 450 & 200 & $\mathbf{0 . 2 5} \pm \mathbf{0 . 0 6}$ \\
\hline 4 & 450 & 500 & $\mathbf{0 . 3 5} \pm \mathbf{0 . 0 5}$ \\
\hline 5 & 600 & 500 & $\mathbf{0 . 3 3} \pm \mathbf{0 . 0 4}$ \\
\hline
\end{tabular}

On the sliding surfaces, concentric scratches highlight abrasive wear. Surface profile, presented in Fig. 5, allows measuring abrasive wear by lost wear material (Table 4) and let show plastic strain of the Stellite (circles zones in Fig. 5).

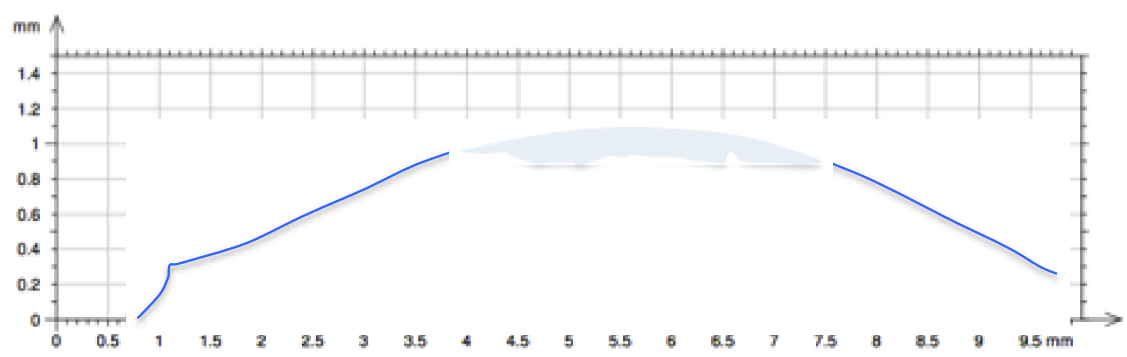

Fig. 5: Surface profile extracted from the 3D-topography of the ring worn surface, after tribological test $\mathrm{n}^{\circ} 4$

Table 4: Wear rate for different temperatures and normal loads

\begin{tabular}{cccc}
$\begin{array}{c}\text { Test } \\
\text { number }\end{array}$ & $\begin{array}{c}\text { Furnace temperature } \\
{\left[{ }^{\circ} \mathbf{C}\right]}\end{array}$ & $\begin{array}{c}\text { Normal load } \\
{[\mathbf{D a N}]}\end{array}$ & $\begin{array}{c}\text { Wear rate } \\
{\left[\mathbf{1 0}^{-\mathbf{4}} \cdot \mathbf{m m}^{\mathbf{3}} /(\mathbf{N} . \mathbf{m})\right]}\end{array}$ \\
\hline 2 & 20 & 500 & $\mathbf{4 . 5}$ \\
\hline 3 & 450 & 200 & $\mathbf{6 . 5}$ \\
\hline 4 & 450 & 500 & $\mathbf{4 . 3}$ \\
\hline 5 & 600 & 500 & $\mathbf{3 . 9}$ \\
\hline
\end{tabular}


Compaction of wear particles and plastic deformation. On cross-sections of the Stellite specimens, four zones can be observed (Fig. 6):

- Oxidized wear particles are present on some parts of the contact surface (Fig. 6: zone 1). These sheared wear particles are then sintered to form layers, which are usually known as "glaze" layers (Fig. 6: zone 2). EDS analyses shows that they are mainly composed by the oxidized disk material (Inconel718).

- On subsurface of the sliding surface and even below glaze layers, the matrix is highly sheared on more or less $50 \mu \mathrm{m}$ depth. This layer can be qualified as plastic flow zone of the Stellite (Fig. 6: zone 3). In this sheared layer, precipitates are broken up into fragments and flow with the matrix.

- Below this highly sheared zone, a gradient of plastic strain is observed. The plastic strain is well highlighted with the precipitates reorientation according to the sliding direction (Fig. 6: zone 4).

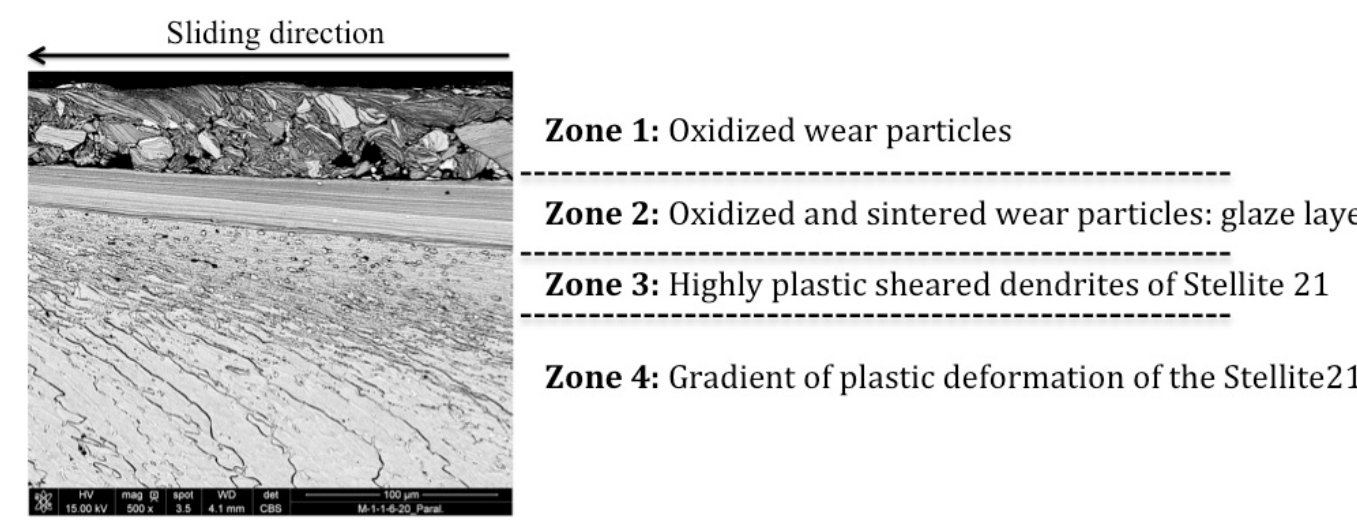

Fig. 6: Cross-section of a ring, after tribological test $n^{\circ} 5$, in a highly damaged area

Subsurface plastic deformation measurement. Fig. 7 compares respectively the microstructure of an unworn area (7a) and the microstructure on a worn area (7b). Under friction shear stresses, the dendrites are plastically deformed and the precipitates are broken up and flow with the matrix.

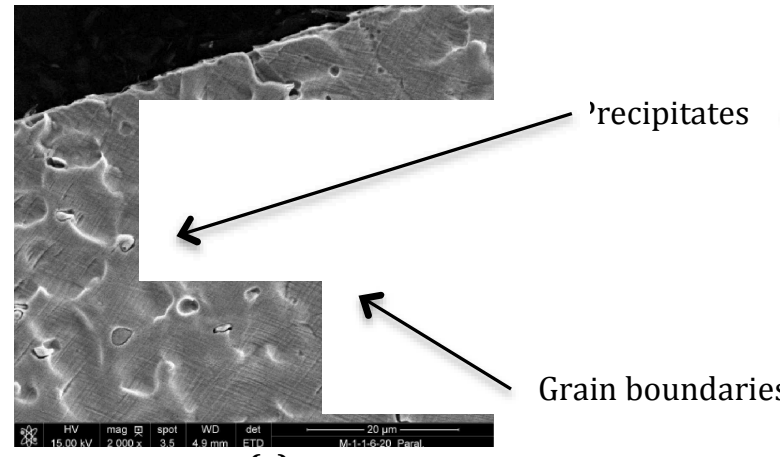

(a)

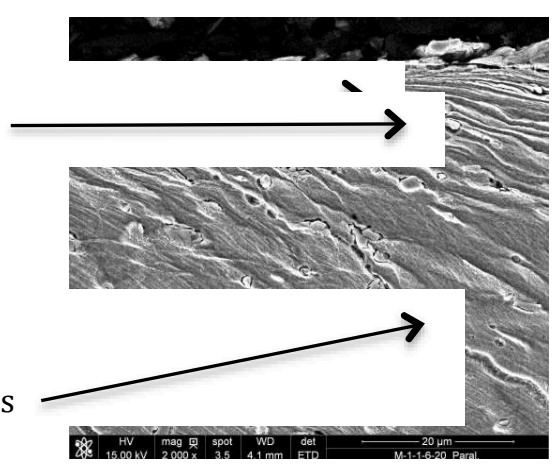

(b)

Fig. 7: Cross-section observations of a ring subsurface, after tribological test $n^{\circ} 5$; (a): unaffected zone, (b): plastic strained zone

Plastic deformation depths are estimated with microstructure observations on worn ring crosssections after polishing and chemical etching (Table 5). We can consider that the thickness of the plastic deformation depends on the measured areas but it is less than $400 \mu \mathrm{m}$ depth. The affected friction depths are approximately similar for each wear test and about $350 \mu \mathrm{m}$. Note that the thickness is highly linked with micro-hardness evolution (Fig. 8). 
Table 5: Plastic deformation depth for different temperatures and normal loads

\begin{tabular}{cccc}
$\begin{array}{c}\text { Tribological } \\
\text { test number }\end{array}$ & $\begin{array}{c}\text { Furnace temperature } \\
{\left[{ }^{\circ} \mathbf{C}\right]}\end{array}$ & $\begin{array}{c}\text { Normal load } \\
{[\mathrm{DaN}]}\end{array}$ & $\begin{array}{c}\text { Plastic deformation depth } \\
{[\boldsymbol{\mu m}]}\end{array}$ \\
\hline 3 & 450 & 200 & $\mathbf{3 6 5}$ \\
\hline 4 & 450 & 500 & $\mathbf{2 7 9}$ \\
\hline 5 & 600 & 500 & $\mathbf{3 4 4}$ \\
\hline
\end{tabular}

Micro-hardness measurements show a Stellite hardening under friction tests. In sheared areas, the Stellite micro-hardness increases up to maximum value of $650 \mathrm{HV}_{0,05}$ (Fig. 8). This last value seems to be the highest level of strain hardening rate which can be measurable in highly plastically sheared zones near the contact surface: regardless the plastic deformation, hardening does not exceed this value or a very close value. The stacking fault energy is considered as weak in Stellites and would facilitate the high level of Stellite work-hardening.

A hardening gradient is then measured in the depth of the plastic shear zone. The evolution of the micro-hardness is related to the plastic deformation of dendritic matrix. In addition, the ultimate value of shear-hardening is in good correlation with that observed in industrial worn hardfaced tools. The glaze layer micro-hardness is very hard and about $950 \mathrm{HV}_{0,05}$.

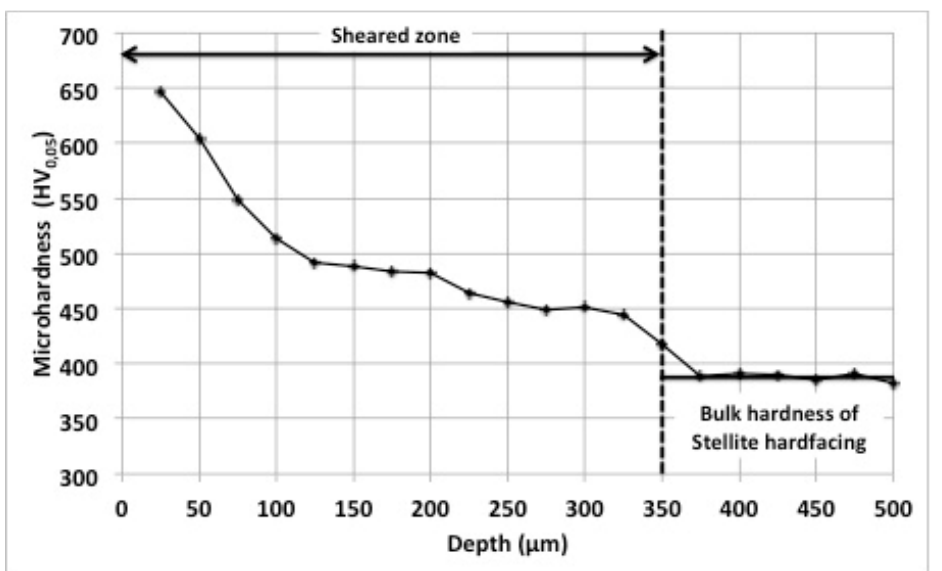

Fig. 8: Gradient of micro-hardness along worn cross-section of a ring, after tribological test $n^{\circ} 4$

Surface texturation. $\theta-2 \theta$ XRD scan of the Stellite worn surface is presented in Fig. 9. The most intense peaks can be indexed in accordance with the FCC structure of the cobalt. The evolutions of the peak relative intensities of the Co-FCC reference, unworn Stellite 21 (MIG processed) and worn surface Stellite 21 are computed on Fig. 10. These measurements show that the planes parallel to the sliding direction are now (111) planes.

Peaks related to the HCP structure of the cobalt are slightly detected but FCC is still the majority cobalt structure. Contrary to literature [6-10], FCC to HCP stain-induced transformation is no evident in our analyses. Either contact pressures are not so high to perform the transformation, either it is too difficult to dissociate the (0001) HCP planes from (111) FCC ones. In order to complete this $\theta-2 \theta$ XRD analyses, texture measurements have been undertaken on the two first peaks of the FCC structure of the cobalt.

Texture measurements on (111) and (200) planes of the worn surfaces show crystallographic modifications. A grain reorientation is well demonstrated by pole figures (Fig. 11 and Fig. 12). After tribological tests, (200) planes which were initially found parallel to the contact surface are tilted by $\pm 45^{\circ}$ from the normal direction (normal direction of the contact surface) towards the sliding direction. (111) planes which were initially not textured are, under friction, almost all parallel to the sliding direction, so their texturation is important under shear stresses. 
In FCC microstructures, the (111) planes are highest atomic density planes and their tilt allows friction by accommodating the greater part of the difference in speed and transmitting the load between the two first bodies.

Persson et al. have also observed, under high load and several strokes, that within the upper friction layer the Co-HCP basal planes have been tilted and aligned parallel to the sliding surface. They assume that this tilt could be responsible of the low friction friction [6].

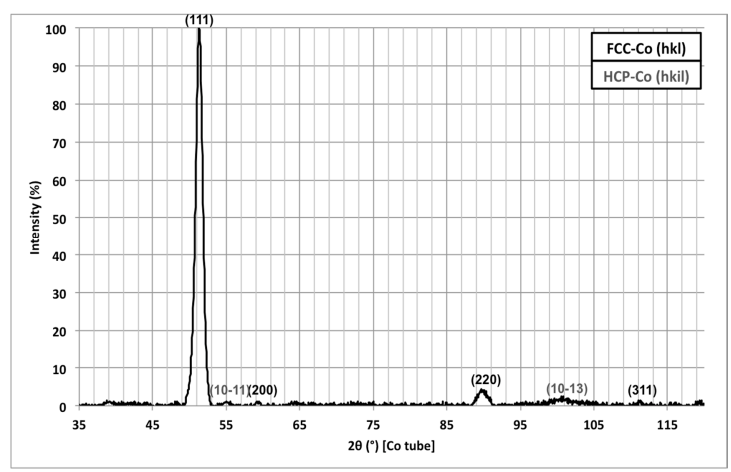

Fig. 9: XRD scan of Stellite 21 worn surface, after tribological test $\mathrm{n}^{\circ} 1$

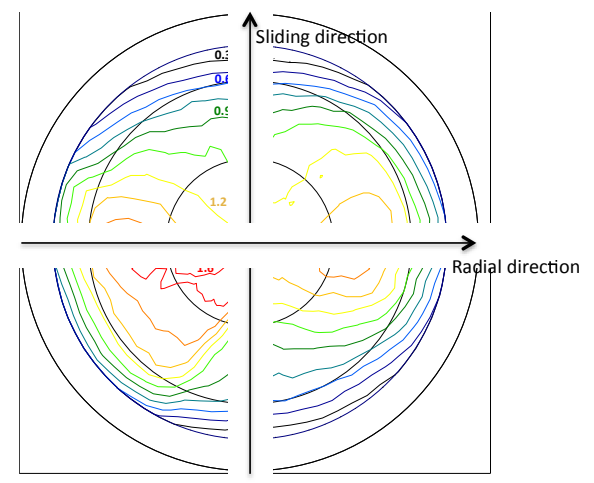

Fig. 11: Pole Figure of (200) plane after tribological test $\mathrm{n}^{\circ} 1$

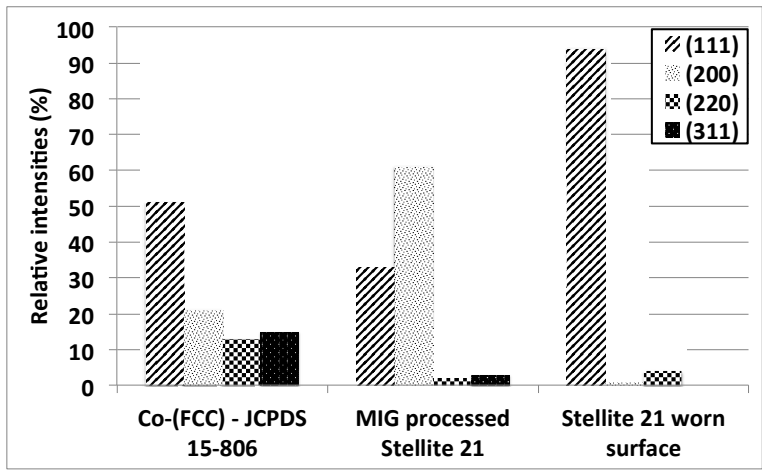

Fig. 10: Comparison of the peak relative intensities of the Stellite 21 worn surface with those of MIG processed Stellite 21 and those of cobalt JCPDS reference

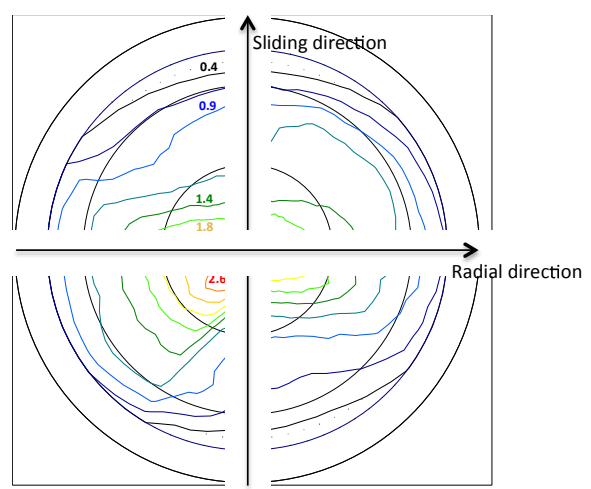

Fig. 12: Pole Figure of (111) plane after tribological test $\mathrm{n}^{\circ} 1$

\section{Conclusions}

This study is focused on wear damage of hardfaced Stellite 21. On a ring on disk tribometer at high load and high temperature, the main wear mechanisms are:

- Stellite 21 shear-hardening under shear stress is well demonstrated and a relationship between the rate of plastic-shear strain and micro-hardness is established. A threshold of the Stellite 21 shear-hardening is observed. Up to this threshold, Stellite 21 flows without any increase of the micro-hardness.

- The Stellite 21 dendritic matrix is able to high plastic deformation and precipitates are broken up and flow with the matrix.

- The Stellite 21 solidification, textured with (200) planes parallel to the substrate-hardfacing interface, is tilted under friction and presents a crystallographic orientation with (111) planes parallel to the sliding surface. 


\section{Acknowledgements}

This work is part of ROOF2 project. It is a FUI12 project labelised by the competitiveness clusters ViaMeca, Aerospace Valley and the European center of ceramics. The ROOF2 project is funded by the Auvergne FEDER, the Auvergne Region, the Allier General Council, the FUI, the Saint-Etienne Metropolis, the Indre General Council, the Limousin Region and the Limousin FEDER.

\section{References}

[1] Atamert, S.; Bhadeshia, H.K.D.H.: Comparison of the Microstructures and Abrasive Wear Properties of Stellite Hardfacing Alloys Deposited by Arc Welding and Laser Cladding, Metallurgical Transactions A, 1989, 20(6), pp. 1037-1054

[2] De Mol Van Otterloo, J.L.; De Hosson J.TH. M. : Microstructural features and mechanical properties of a cobalt-based laser coating, Acta Materilia, 1997, 45(3), pp. 1225-1236

[3] Radu, I.; Li, D.Y.; Llewellyn, R.: Tribological behavior of Stellite 21 modified with yttrium, Wear, 2004, 257(11), pp. 1154-1166

[4] Shin, J.C.; Doh, J.M.; Yoon, J.K.; Lee, D.Y.; Kim, J.S.: Effect of molybdenum on the microstructure and wear resistance of cobalt-base Stellite hardfacing alloys, Surface and Coatings Technology, 2003, 166(2-3), pp. 117-126

[5] Fouilland, L.; El Mansori, M.; Gerland, M.: Role of welding process energy on the microstructural variations in a cobalt base superalloy hardfacing, Surface and Coatings Technology, 2007, 201(14), pp. 6445-6451

[6] Persson, D. H. E.: On the Mechanisms behind the Tribological Performance of Stellites, Digital Comprehensive Summaries of Uppsala dissertations from the Faculty of Science and technology 129,2005

[7] Persson, D. H. E.; Jacobson, S.; Hogmark, S.: Antigalling and low friction properties of a laser processed Co-based material, Journal of laser applications, 2003, 15(2), pp. 115-119

[8] Kashani, H.; Amadeh, A.; Ohadizadeh, A.: Effect of temperature on the strain induced $\gamma \rightarrow \varepsilon$ phase transformation in Stellite 21 during wear test, Materials Science and Engineering A, 2006, 435-436, pp. 474-477

[9] Kashani, H.; Sadeghi Laridjani, M.; Amadeh, A.; Khodagholi, M.; Ahmadzadeh, S.; The influence of volumetric dilution on the strain induced $\gamma \rightarrow \varepsilon$ martensitic transformation in GTAW processed Co-Cr-Mo alloy, Materials Science and Engineering A, 2008, 478(1-2), pp. 38-42

[10] Huang, P.; López, H.F.: Strain induced $\varepsilon$-martensite in a Co-Cr-Mo alloy: grain size effects, Materials Letters, 1999, 39, pp. 244-248

[11] Bhansali, K.J.; Miller, A.E.: The role of stacking fault energy on galling and wear behavior, Wear, 1982, 75(2), pp. 241-252

[12] Fouilland, L.; El Mansori, M.; Massaq, A.: Friction-induced work hardening of cobalt-base hardfacing deposits for hot forging tools, Journal of Materials Processing Technology, 2009, 209(7), pp. 3366-3373

[13] Kashani, H.; Amadeh, A.; Ghasemi, H.M.: Room and high temperature wear behaviors of nickel and cobalt base weld overlay coatings on hot forging dies, Wear, 2007, 262(7-8), pp. 800806

[14] Farhani, M.; Amadeh, A.; Kashani, H.; Saeed-Akbari, A.: The study of wear resistance of a hot forging die, hardfaced by a cobalt-base superalloy, Materials forum, 2006, 30, pp. 212-218 